\title{
THE ESTIMATION OF PHENOL IN CRUDE CARBOLIC ACID AND TAR OILS. ${ }^{1}$
}

\author{
BY \\ JOHN MORRIS WEISS, B.S., B.A.,
}

Member of the Institute.

A PROBLEM which is occasionally presented to the chemist engaged in the examination of various tar products is the determination of actual phenol $\left(\mathrm{C}_{6} \mathrm{H}_{5} \mathrm{OH}\right)$ in the substance under consideration. Usually all that is required is the estimation of total phenols, generally called "tar acids." These tar acids consist of a complex mixture of phenol, cresol, and various higher homologues, and their quantitative estimation in toto is always based on their common chemical propenty of solubility in a solution of caustic alkali. Sometimes, however, it is necessary to proceed further, and ascertain how much of these tar acids is real phenol.

At present, so far as the writer has been able to learn, there is no satisfactory solution of this problem in the literature. Many tests for qualitative distinction of phenol, cresol, and the higher homologous oxygenated aromatic hydrocarbons have been proposed. Some of these are of very doubtful value, even qualitatively, but none are all susceptible of even approximate quantitative application.

The only real attempt in this field was that of Charles Lowe (see Lunge's Coal Tar and Ammonia, Fourth Ed., pp. 608-9). This is proposed for crude carbolic acid, and is more a specification for material than a method of analysis. Briefly, it consists in plain distillation in a retort, with no attempt at fractionation, and subsequent determination of the melting point of an arbitrary fraction. This fraction is a definite volume per cent. after removal of the water. The percentage of phenol is determined by adjusting a mixture of phenol and cresol (mixture of the three isomers) to have the same melting point. This is a method

"Communicated by the author. See also "Note on the Rideal-Walker Phenol Control," by J. T. A. Walker and J. M: Weiss, Journal Frankin INSTITUTE, I74, IOI. 
evirlently only applicable when the percentage of phenol is large and when there is no disturbing influence of higher homologues.

The writer, in attacking this problem, decided that chemical properties would be inferior to physical properties as a means of distinction, in view of the fact that the material sought existed in mixture with bodies very closely related chemically to it. To separate phenol from all bodies except the next higher homologues, the cresols, is a comparatively simple task, and one which can be accomplished in a convenient and easy manner. Further, if the physical properties of a large number of varying mixtures of phenol and cresols are known, the estimation of the phenol is possible, the exactness varying with the number of such known mixtures. This really is the gist of the work undertaken by the writer, and the practical results of the investigation are presented in this paper.

The work was complicated by the fact that the three isomeric cresols exist with varying physical properties, and the possibilities of mixtures with four variables are enormous. This phase of the question, as will be seen later, was considerably simplified.

As a preface, it may be well to give the physical properties of phenol and the cresols, as taken from Van Nostrand's Chemical Annual:

\begin{tabular}{|c|c|c|c|}
\hline Phenol & $\begin{array}{l}\text { Melting point. } \\
\ldots 42.5^{\circ}-43^{\circ} \mathrm{C} \text {. }\end{array}$ & $\begin{array}{c}\text { Boiling point. } \\
\text { I } 8 z .6^{\circ}\end{array}$ & $\begin{array}{c}\text { Specific gravity. } \\
\text { 1.0677 }\end{array}$ \\
\hline o Cresol & $\ldots 30^{\circ}$ & $\operatorname{IgI}^{\circ}$ & $1.05 \mathrm{TI}$ \\
\hline$m$ Cresol & ‥ $3-4^{\circ}$ & $202^{\circ}$ & r.0390 \\
\hline$p$ Cresol & $\cdots 3^{\circ}$ & $202^{\circ}$ & I. .0390 \\
\hline
\end{tabular}

The specific gravities are given for the cresols at $15^{\circ} / 15^{\circ}$ and for phenol at $35^{\circ} / 35^{\circ}$. Beilstein gives the following figures:

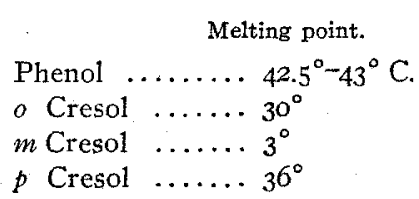

Boiling point.
$178.5^{\circ}-184 \cdot 1^{\circ}$
$190.8^{\circ}$
$202.8^{\circ}$
$201.8^{\circ}$

Specific gravity at $0^{\circ} \mathrm{C}$. I.0906 1.0578 1,0498 1.0522

As may be seen, the specific gravities and boiling points of $m$ and $p$ cresols are quite close together, and these two always occur together in commercial mixtures; therefore, to simplify 
matters, a mixture of these was used instead of the pure separate materials, thereby reducing the variables to be considered to three. The $m$ and $p$ cresols cannot be separated by physical means, and to prepare them pure is a very extensive and difficult task. As to the accuracy of the above figures given by various authorities for the physical constants of these substances, the writer feels that in many cases they are inaccurate and will take up this phase of the subject later.

The phenol used was prepared synthetically from pure benzene, the $o$ cresol by fractional extraction of a mixture of cresol, with caustic soda solution, subsequent crystallization from petroleum ether, and final fractional distillation. The mixture of $m$ and $p$ cresol was separated by a very careful and efficient fractionation of a fraction of but two or three gallons taken from a works still handling large charges. The tests of these materials are given below:

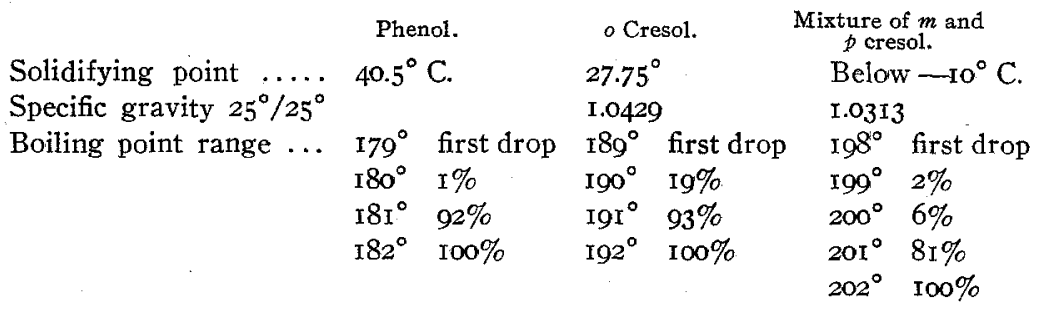

To obtain some idea of the purity of these substances, the effect of 5 per cent. of $o$ cresol or the $m-p$ cresol on the phenol boiling point was determined, as follows:

$\begin{aligned} & 95 \% \text { phenol, } 5 \% \text { o cresol. } \\ & 177^{\circ} \text { first drop } \\ & 178^{\circ} 2 \% \\ & 179^{\circ} 4 \% \\ & 180^{\circ} 9 \% \\ & 181^{\circ} 88 \% \\ & 182^{\circ} 96 \% \\ & 184^{\circ} 100 \%\end{aligned}$

$\begin{array}{cl}95 \% \text { phenol, } 5 \% & m-p \text { cresol. } \\ 178^{\circ} & \text { first drop } \\ 179^{\circ} & 7 \% \\ 180^{\circ} & 10 \% \\ 181^{\circ} & 23 \% \\ 182^{\circ} & 85 \% \\ 183^{\circ} & 93 \% \\ 185^{\circ} & 97 \% \\ 190^{\circ} & 100 \%\end{array}$

Similarly, o cresol with 5 per cent. phenol addition had a range in boiling point of from $186^{\circ}$ to $192^{\circ} \mathrm{C}$. The method 
for taking boiling-point range was a distillation of roo c.c. in a Jena flask protected by an asbestos ring and connected to a 24-inch condenser. Naturally, there is a certain lag of the thermometer at the start and a slight superheating at the end which tends to enlarge the range, even of a pure substance. The presence of a trace of water, hard to avoid in such hygroscopic substances, also causes a slight amount of material to distil below its true boiling point. On the phenol, practically 90 per cent. boiled between $180^{\circ}$ and $180.5^{\circ}$, and no fraction could be obtained having a higher solidifying point than $40.5^{\circ} \mathrm{C}$., no matter how many times it was distilled. The same was true of the ortho-cresol on distillation-no fraction could be obtained with a solidifying point over $2734^{\circ} \mathrm{C}$. These solidifying points were taken on a large quantity of material with the thermometer in the liquid. The thermometer was a Jena glass normal thermometer that has been checked by the United States Bureau of Standards. The writer therefore considered his materials practically absolute, and deemed that the high figures given by earlier investigators as to melting point were inaccurate either because of erroneous thermometers or from the use of too small quantities of material.

A large number of mixtures were made with the above materials, using 0,5 , 10, 20, 30, 40, 50, 60, 70, 80, 90, and 95 per cent. phenol, and for each percentage of phenol eleven variations of the proportions of $o$ and $m-p$ cresols were used, making in all ${ }_{3} 32$ mixtures. The boiling-point range, specific gravity, and solidifying point of all these mixtures were then determined.

For the purposes of this paper it is unnecessary to detail all the figures obtained on these mixtures, but only to give those which would be of practical value to the worker. It was found that for all but unusual cases the determinations of solidifying point and specific gravity were enough to characterize the mixtures as to their percentage of phenol, and that a determination of boiling-point range was superfluous.

The procedure for determining the percentage of phenol in a crude carbolic acid or a tar oil should be as follows: A definite volume of material should be taken, sufficient to give 300 c.c. of total phenols (tar acids). This should then be treated with 
sufficient caustic soda solution to dissolve all tar acids. The solution of acids in soda is carefully separated from the neutral hydrocarbons and then steam-distilled until no oil is present in the distillate. This insures the removal of all material not tar acids. The soda solution is then cooled, brought into a separatory funnel, and acidified with $40^{\circ}$ Baumé sulphuric acid. The mass is allowed to settle, and the lower layer of sodium sulphate discarded. The upper layer of phenols is brought into a distilling flask with a Hempel tube, and distilled up to $170^{\circ} \mathrm{C}$. vapor temperature. This removes water, but a small amount of acid is carried over in the process. This latter is separated from the water and returned to the flask. The distillation is then continued, and two fractions taken off, the first up to $190^{\circ} \mathrm{C}$. and the second from $190^{\circ} \mathrm{C}$. to $202^{\circ} \mathrm{C}$. This second fraction is redistilled, taking all up to $197^{\circ} \mathrm{C}$., and is added to the $190^{\circ}$ fraction obtained in the first distillation. This combined fraction contains all the phenol and none of the homologues above cresol, and is tested for solidifying point and specific gravity.

The solidifying point is taken on about 50 c.c. in a testtube with the thermometer in the liquid and cooling until separation of crystals occurs. At this point there is a constant temperature for a short period which is taken as the solidifying point. If the material supercools, crystallization may be brought about by addition of a minute crystal of phenol: in this case the temperature rises as the crystals separate, and the highest point reached is taken as the solidifying point. The specific gravity should be taken on a Westphal balance at $25^{\circ} \mathrm{C}$. and referred to water at the same temperature.

These figures are compared with those given below, the per cent. of phenol noted, and the result figured back to the original material. In considering these figures, it should be remembered that $o$ cresol tends to simultaneously raise both the specific gravity and melting point of a mixture, and therefore up to a certain point with increase of melting point the gravities corresponding to the same percentage of phenol also increase.

Various mixtures which may occur as a result of the above procedure are given in a rough classification. 
688 John Morris Weiss.

Solidifying point below $o^{\circ} C$.:

Speciflc gravity $\frac{25}{2}$.

up to 1.032

I.035

I.040

I.043

I.047

I.049
Per cent. phenol:

o

5

IO

20

30

40

Mixtures above 40 per cent. phenol have a solidifying point over $\mathrm{O}^{\circ} \mathrm{C}$.

Solidifying point $0-5^{\circ} \mathrm{C}$.:

Specific gravity $\frac{25}{2}$.

up to 1.038

1.040

1.042

1.045

1.048

I. 0.52
Per cent. phenol.

0

5

IO

20

30

40

Solidifying point $5-10^{\circ} \mathrm{C}$.:

Specific gravity $\frac{25}{25}$

I.039

I. $04 \mathrm{I}$

I.043

I. .047

I.0.50

I.053

I. 055
Per cent. phenol.

0

5

IO

20

30

40

50

Solidifying point ro- $15^{\circ} \mathrm{C}$.:

Specific gravity $\frac{25}{3}$
1.040
1.042
1.044
1.048
1.051
1.054
1.057

Per cent. phenol.

0

5

10

20

30

40

50 
Solidifying point $I 5-23^{\circ}$ C.:

$\begin{array}{cc}\text { Specific gravity } \frac{25}{2} \frac{5}{5} . & \text { Per cent. phenol. } \\ \text { I.04I } & 0 \\ \text { I.043 } & 5 \\ \text { I.045 } & 10 \\ \text { I.048 } & \text { I0 } \\ 1.052 & 20 \\ \text { I.055 } & 30 \\ \text { I.058 } & 30 \\ \text { I.061 } & 40 \\ & 50 \\ & 60\end{array}$

Solidifying points above $23^{\circ} \mathrm{C}$.:

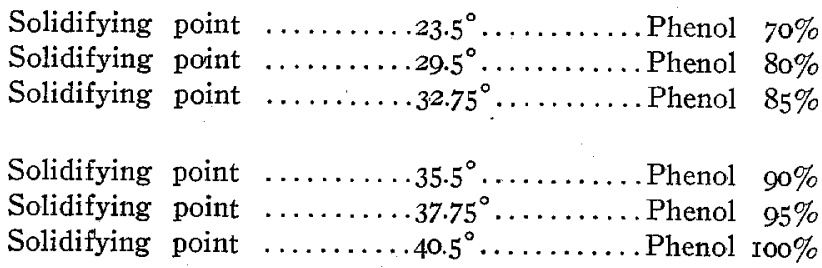

With solidifying points above $23^{\circ} \mathrm{C}$. it was found that the variations in percentage of the cresols among themselves did not affect the solidifying point for any particular percentage of phenol.

Some mixtures would not be covered correctly by the above tables. For example, a mixture of 20 per cent. phenol and 80 per cent. $m-p$ cresol melts below $0^{\circ}$ and has a gravity of I.040. This would indicate, as above, only ro per cent. phenol. But such a mixture could never. occur in a fraction obtained from natural materials, and therefore it is unnecessary, for practical analysis, to cover this ground. If it were necessary, the boiling points would be distinguishing, but to introduce these constants would make complications; and would not be of practical value for the purposes this paper is designed to cover.

In using these tables, the worker must exercise some judgment, as if a solidifying point were barely over $0^{\circ} \mathrm{C}$. and the specific gravity were r.040 at $25^{\circ} \mathrm{C}$., the percentage of phenol would be more than 5 per cent. and less than ro per cent., and about 7.5 per cent. should be taken. Conversely, near the upper end of a range of solidifying point the gravity would indicate Vor. CLXXIV, No. 1044-47. 
slightly less phenol than the figure given. If the figures are used intelligently and with real insight into their meaning, an estimation on the fraction within 2.5 per cent. of the true value should be readily obtained. Depending upon the total amount of tar acids in the original material, the results on the basis of the latter should be accurate between 0.2 per cent. and I.5 per cent., and this is sufficiently close for all ordinary purposes.

The Disturbing Influence of Solar Radiation on the Wireless Transmission of Energy. Nikola Tesla. (Elec. Rev. West. Elect., 1xi, 34.) -The weakening of the impulses in wireless transmission is not due to ions liberated by sunlight, but to the evaporation of water on the hemisphere of the earth toward the sun, the conducting particles carrying off into the ground more or less of the electrical charges imparted. The Tesla system of transmitting energy through the earth is contrasted with the Herzian wave system.

Collection of Radium Emanation from Spring Waters. $H$. Greinacher. (Univ. Zurich Phys. Zeit., xiii, 435.) -In collecting water samples, loss of the emanation is avoided by the use of an exhausted glass globe with a glass stopcock instead of the ordinary container. The emanation is separated by boiling the water in the glass globe while it is directly connected to a partially-exhausted fontactoscope suitably modified. The use of the exhatsted container insures the collection of water samples without loss of the emanation by inexperienced persons.

Meeting of the International Radium Standard Commission in Paris. O. Hahn, St. Meyer, and E. v. Schweidler. (Physik. Zeit., xiii, 524.) - A sample of pure anhydrous radium chloride prepared by Mme. Curie, and weighing $21.99 \mathrm{mg}$., was compared with three standard samples of radium chloride of the highest purity prepared by $\mathrm{O}$. Hoenigschmid, of the Radium Research Institute of the Imperial Academy of Sciences of Vienna, weighing, respectively, IO.II, 3 I.I 7 , and $40.43 \mathrm{mg}$. The activities of the several standards were found to agree within the limits of experimental error, 2 parts per rooo. Mme. Curie's standard was declared the official international standard, and is to be kept in the International Bureau of Weights and Measures in Sèvres, Paris. The Imperial Academy of Sciences of Vienna will be requested to deposit one of its standards, weighing $31.17 \mathrm{mg}$., in Vienna, as a supplementary standard. The commission formulated regulations for providing governments with secondary standards. 